\title{
Cooperative Technology Innovation of Shipbuilding Industrial Cluster based on the Symbiosis Theory
}

\author{
Long Chen \\ School of Economics and Management, Jiangsu University of Science and Technology, Zhenjiang, Jiangsu Province, China \\ 493735206@qq.com.
}

\begin{abstract}
In this paper, in the perspective of three basic elements of symbiosis theory, symbiosis unit, symbiosis environment and symbiosis interface of cooperative technology innovation of the shipping industrial cluster were analyzed. Based on this theory, the author analyzed the case of shipbuilding industrial cluster in Jiangsu Province. Combined with the present situation and trend of development of cooperative technology innovation of shipping industrial cluster in Jiangsu province, he summarized the symbiotic model of it, put forward the development measures and hoped to be able to find a cooperative technology innovation model of shipping industrial cluster which is suitable for China's national conditions.
\end{abstract}

Index Terms - Symbiosis theory, Shipping enterprises, Industrial cluster Cooperative technology innovation

Shipbuilding industry is the modern integrated industry to provide equipment for water transport, marine development and national defense construction and other industries, it is a strategic relationship between the long-term interests and basic industry of the country, and also it is an important symbol measure of a country or region's economic competitiveness. In 2012, China shipbuilding capacity 60.21 million DWT, accounting for $40.7 \%$ of world market share; there are 20.41 million DWT new orders, accounting for $43.6 \%$ of world market share; handheld orders 106.95 million DWT, accounting for world market share $41.5 \%$, but compared with other shipbuilding country, China shipbuilding industry is relatively backward technology in general, shi is not consistent with the world's largest shipbuilding country, the urgent thing need to upgrade and technological innovation, how to find an innovative path of development to achieve sustainable development, It is importance and urgency.

Industry cluster collaborative technology innovation value is that it can give full play to the synergy about cluster's various elements of the process of innovation, be a comprehensive overall effect, It provide an effective way of common technologies for major industry innovation and overcome the "go it alone type independent innovation" limitations, It greatly improving the efficiency of innovation and has become an important guarantee for the sustainable development of industrial clusters. Based on Symbiosis Theory perspective, The example of ship industry cluster from Jiangsu Province, to the symbiotic theory, industrial clusters around technology innovation and collaborative research to identify, find a suitable way for China industrial clusters collaborative innovation model It have great significance to improve the efficiency of technological innovation and promote industrial restructuring and upgrading.

\section{Review of Relevant Literature}

In recent years, the symbiotic theory applied to cluster research has made some progress by scholars ${ }^{[1-4]}$,symbiosis theory can better reveal the formation and development of industrial clusters to some extent, but they have less research on collaborative technology innovation of industrial clusters, based on the symbiotic theory of industrial clusters to research collaborative innovation are more less.1970s, Nelson and Winter the American scholars founded the evolutionary innovation, it promotes the integration of technology innovation and institutional innovation. Daft proposed the dual-core model, he believes enterprise innovation is divided into technological innovation and management innovation, only two innovative synergistic can make innovation performance best ${ }^{[5]}$; Shinn and Lamy researched collaborative mode between universities and enterprises ${ }^{[6]}$; Carfiss and Eric expanded the scope of technological innovation, they added costs and communication costs in the mode, proposed open collaborative innovation mode different from single user or enterprise innovation mode ${ }^{[7]}$; Niki add information technology into collaborative to research technological innovation, present a hybrid collaborative knowledge mode on the level of information technology ${ }^{[8]}$. Chinese scholar Dan Liu analysis technological innovation activities of industrial cluster of synergy, thinks technological innovation and industry cluster is a collaborative innovation process ${ }^{[9]}$; Luke Bing and Wei Guo analysis the formation mechanism of industrial clusters, given the knowledge of the market and the industry cluster concept of total factor collaborative innovation model ${ }^{[10]}$; Peng Zhen Chen put forward the idea based enterprise collaboration technology innovation to improve the level of overall industry clusters after viewing the current cluster enterprises in technological innovation problems and think collaborative enterprise technology innovation cluster ${ }^{[11]}$. The above article about shipbuilding industrial cluster collaborative technology innovation, present research questions, but many of these studies have ignored the particularity of specific industries. Because this research paper takes concrete and feasible theory (such as symbiosis theory),will analysis the case of Jiangsu shipbuilding industry cluster for collaborative innovation, this innovative research techniques will become the new trend of industrial clusters collaborative. 


\section{Analysis of the Symbiosis of Shipbuilding Industrial Cluster Cooperative Technology Innovation}

\subsection{The symbiotic unit of technology innovation synergy of shipbuilding industrial cluster}

In the symbiosis theory, symbiotic unit is the basic energy form or exchange unit of the symbiotic or symbiotic relationship. If take the cooperative technological innovation as a symbiosis of shipbuilding industrial cluster, the symbiotic unit is symbioses the ship enterprises, government departments, financial institutions, universities and research institutions in the supporting of ship collaborative technology innovation, or a symbiotic relationship and exchange unit, they form the basic material conditions of technology innovation symbiosis cooperation of shipbuilding industrial cluster.

\subsection{Symbiosis degree and association degree}

Symbiosis degree and association degree are two important indexes for technology innovation symbiosis unit features of coordination reaction of shipbuilding industrial cluster ${ }^{[12]}$. Symbiosis symbiotic degree refers to the two symbiotic units and the correlation of symbiotic system quality parameters change. Assume the existence of symbiotic units $\mathrm{A}$ and $\mathrm{B}$, parameters were as $X_{i}$ and $X_{j}$, quality parameters were as $Z_{i}$ and $Z_{j}$, the symbiotic degree of $\mathrm{A}$ and B was represented by $\delta_{i j}$ :

$$
\delta_{i j}=\frac{d_{z_{i}} / d_{z_{i}}}{d_{z_{j}} / d_{z_{j}}}\left(d_{z_{j}} \neq 0\right)
$$

$\delta_{i j}$ Is the rate of symbiotic unit $\mathrm{A}$ of the quality parameters caused by the change of rate of symbiotic unit B of the quality parameters? If $Z_{i}$ and $Z_{j}$ were the primary qualitative variables of A and B respectively, then $\delta_{i j}=\delta_{i j}^{m}$, we called they were characteristics of the symbiotic of $\mathrm{A}$ and B.

$$
\delta_{i j}^{m}=\frac{d_{z_{m i}} / Z_{m i}}{d_{z_{m j}} / Z_{m j}} \quad\left(d_{z_{m j}} \neq 0\right)
$$

Correlation of symbiotic unit is the symbiotic relationship between the units. These two indicators have a certain difference in definition, but it is in the characterization of symbiotic relationship between units. Symbiosis of the shipbuilding industry cluster cooperation for technology innovation, scientific research institutions and the enterprise quality parameters is essential to them a series of activities, that is the key indexes of input and output ${ }^{[13]}$, Scientific research institutions in general researchers and fund etc. output for talent, application achievements (patent, technology) and basic results, they are quality parameters of scientific research institutions; The ship enterprises funds, personnel, technology, material and energy into products and profits of output, capital, talent, technology, the profit can be called the quality parameters of ship enterprises. Obviously, symbiosis symbiotic unit shipbuilding enterprises caused by a change in quality parameters of unit of scientific research institutions, If companies choose ship symbiotic partner research institutions, and put more money as research funding, would bring higher economic value added products to ship enterprises, bring more profit for enterprise, will have the effect of $1+1>2$. This shows on the one hand, there must be a link between the symbiotic and symbiotic system.

\subsubsection{Symbiotic density}

In the symbiotic system, symbiotic density mainly reflects the quantity of symbiotic units in the symbiotic relationship. During the development of the symbiotic system identified by cooperatively technological innovation within shipbuilding industrial cluster, symbiotic units can't increase unlimitedly even if they have all the symbiotic conditions, because the increase of the density does not necessarily cause the increase of symbiosis energy, and may result in the increase of symbiotic loss on the contrary. Therefore, in the cooperatively technological innovation within shipbuilding industrial cluster, the balance of symbiotic density is very important and "boundary condition" of cooperative units for technological innovation among shipbuilding enterprises is crucial. If the scope of innovation cooperation is too small, the necessary conditions supporting technological innovation can't be formed. And if the scope of innovation cooperation is too big, technological innovation cooperation will have vague extensions and overblown connotations.

\subsection{Symbiotic environment of cooperatively technological innovation within shipbuilding industrial cluster}

For shipbuilding industrial clusters, the symbiotic environment refers to all the combined factors except symbiotic units. These factors usually interact with each other through the mutual flow of material, energy and information and can be divided into positive, neutral and negative environments ${ }^{[14]}$ according to their influence on symbiotic units. Correspondingly, the reactions of cooperatively technological innovation within shipbuilding industrial cluster are also shown as positive, neutral, and negative.

In cooperatively technological innovation, ideally shipbuilding industrial clusters taking part in technological innovation and their symbiotic environment have a kind of relationship identified as reciprocally positive influence on each other, and incentive measures in both directions can be adopted. In order to ensure the continuous cooperation in technological innovation, we should establish the following mechanisms including incentive mechanism, constraint mechanism and benefit-sharing mechanism. We not only should strengthen the enthusiasm of scientific research institutions, government departments and financial institutions in promoting technological innovation cooperation, but also must regulate interests' transfer among the parties under the premise of equality, mutual benefit, cooperation, in order to achieve fair and reasonable distribution of the overall interests within shipbuilding industrial clusters. 


\subsection{Symbiotic interface of cooperatively technological innovation within shipbuilding industrial cluster}

Symbiotic interface is the media, channel, and carrier through which material, information and energy are transferred among different symbiotic units, and is the foundation for the formation and development of symbiotic relationship ${ }^{[15]}$, significantly influencing the equilibrium of symbiotic system. In this symbiotic system of cooperatively technological innovation within shipbuilding industrial cluster, technological innovation cooperation is operated by the flow of energy, which includes personnel flow, technique flow, capital flow, information flow, energy flow, traffic flow, etc. The material basis realizing these energy flows is composed by infrastructure, transportation network and information network within the shipbuilding industrial cluster. The quality and capacity of these infrastructures directly affect the time needed for energy exchanges between symbiotic units in the cluster, and further affect the operation cost of the technological innovation cooperation. Therefore, improving the level and quality of infrastructures is the prerequisite of optimizing symbiotic interface of cooperatively technological innovation within shipbuilding industrial cluster and promoting the technological innovation cooperation between different symbiotic units.

\section{Case study of Shipbuilding Industry Cluster in Jiangsu Province}

\subsection{Analysis of cluster development of shipbuilding industry in Jiangsu Province}

From 2008 to 2012, the shipping industry in Jiangsu province remained stable development, and the three major shipbuilding indicators ranked first in the country, which made Jiangsu province the largest shipbuilding province in the country. You can say the center of world's shipbuilding is China, and the center of China's shipbuilding is Jiangsu .The vigorous development of shipbuilding industry of Jiangsu province created favorable conditions for the formation of industrial clusters in Jiangsu province. At present, there has been six distinctive ship industry clusters, including Nanjing Qi Xia ship industry cluster, Nan Tong ship industry cluster, Yang Zhou ship industry cluster, Zhenjiang(Runzhou) ship industry cluster, Tai Zhou inland river ship industry cluster and Jingjiang ship industry cluster.

Since the outbreak of the global financial crisis in 2008, it has brought huge impact on shipbuilding industry. At present, the inside and outside of China's shipbuilding industrial development have changed a lot, heading the stage from rapid development to fierce competition, from quantity expansion to quality improvement. Promoting cluster development of shipbuilding enterprises, accelerating industry transformation of shipbuilding enterprises, adjusting the structure of enterprise, integrating resources, cutting the cost to increase profits, producing high technology, high quality, high economic value ship, developing new markets are the turning points for shipbuilding enterprises in Jiangsu Province to survive between fierce competition.

\subsection{Symbiosis mode of Cooperative technology innovation of shipbuilding industry in Jiangsu Province}

The symbiosis mode of Cooperative technology innovation of shipbuilding industry is a mode which shipbuilding industry uses the net advantage of cluster innovation to make technological innovation. The cluster innovation nets of shipbuilding industry are these formal and informal relational nets based on Specialization which are formed by the concentration of shipbuilding industry, scientific research institutions and universities, government sector, financial institutions and other mediation in a regional, exchanging resources, energy and information with external environment. It is a foundation platform for the shipbuilding industry and it's supporting enterprises to get information about market, technology and etc. This symbiosis mode of technology innovation is shown as Figure 1.

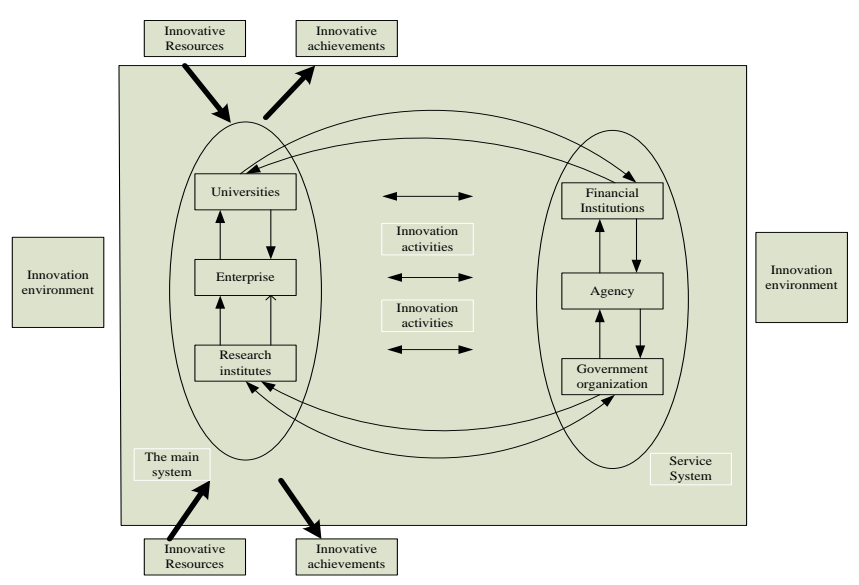

Fig. 1 symbiotic model of ship industrial cluster's cooperative technological innovation

We take Nan Jing Qixia ship industrial cluster in Jiangsu Province as an example. Nan Jing ship industrial cluster consists of four major shipbuilding bases, namely Ba Gua Zhou shipbuilding base, Long Pao shipbuilding base, Wu Jiang shipbuilding base and Yang Jiang shipbuilding base. Ba Gua Zhou is the leading shipbuilding base in Nan Jing shipbuilding industrial clusters, which cooperative technological innovation is not only reflected between ships and their ancillary enterprises, but also between shipbuilding enterprises and other subjects.

On the one hand, they actively build innovative platforms, use the specific geographical advantage to build bridges between research institutions, universities and enterprises, so as to build network of industrial cluster innovation. In 2008, with the help of Science and Technology Bureau in Qi Xia district and other relevant departments, Bo Gua Zhou shipbuilding base connected with Nanjing University of technology, Ying Tian College and other colleges to help Nanjing Wu Jia Zui Shipbuilding Co. Ltd to ggetin contact with these schools and finally combined into a marine technology development team. On the other hand, they focus on the connection with financial institutions and strengthen the combination with Ying Mao rural microfinance 
company to help shipbuilding companies solve the financial crisis. By January 2011, the company has make loans 104 times; total lending is 262.5 million Yuan and the percentage that more than 3 months loan term reaches $100 \%$.

\subsection{Specific measures on cooperative technological innovation of ship industry cluster in Jiangsu Province}

Ship industry is a capital, technology and labor-intensive comprehensive industry, its development can not only promote the growth of steel, machinery, electronics, chemical industries and other industries, but also optimize the industrial structure, improve the innovation and application capability of high technology, promote urbanization construction, alleviate employment pressure and increase export revenue. Combined with current development of ship industrial cluster's cooperative technological innovation industrial clusters in Jiangsu province, we propose the specific measures on developing cooperative technological innovation of ship industrial cluster.

First, play the role of government regulation; increase the intensity efforts to support the ship industry innovation. Healthy development of the shipping industry clusters need to rely on the government to co-ordinate and industry associations' coordination. Moreover, government support policies directly affect the shipping industry to cultivate capability of independent innovation, the impact of government action on the shipbuilding industrial cluster collaborative technology innovation focused on three ways. The first is the government financial input, It can effectively improve the technological innovation capability of enterprises ship; followed is government procurement, government procurement is an effective way of funding will be used to stimulate technological innovation, It is called public procurement; finally, tax incentives, it is the most direct and effective policy tool to incentive technological innovation.

Second, attention to personnel training and introduction, more investments in technology and promote independent innovation. Establishment technology innovation system of shipbuilding enterprises as the main stay, give full play to the Institute and outside ship provinces and universities' technological advantage, Enterprises introduce high-tech talent, accelerate training a group of high personnel; they uses various channels to raise funds for increasing investment and establishing key technology platform to share resource.

Third, establish reasonable hierarchy ship repair and shipbuilding industry. The existing industrial clusters based on the ship industrial parks in Jiangsu Province, building public technical service centers, marine accessory products trade center, logistics center and distribution services. Improve domestic service network to consolidate and expand the domestic market. First, the product is first, the main equipment is the backbone and carry out the new system; Second, adhere to digest and absorb innovative ideas to combine innovation; Third, the implementation the Trinity domestic innovation strategy of the introduction, development and transformation.

\section{Conclusions}

At present, China's shipbuilding industry cluster is still in the preliminary development stage; the technological innovation network of shipbuilding industry cluster is not fully built up; cluster enterprises lack self-developed core technology and innovation and the benefits of technological innovation is not obvious. Technological innovation of industrial clusters has become an important choice at this stage of technological innovation, and collaborative technology innovation of shipbuilding industry cluster gradually shows various characteristics including diversification of innovation subject, collaboration of innovation process and network of innovative behavior, which requires ships collaborative technology industrial clusters corresponding occurs corresponding changes. In the shipbuilding industrial cluster collaborative technology innovation process, companies can adopt comprehensive study, efficient coordination, mutualism management, cultivate and build self-developed shipbuilding enterprise core technology system and thus improve the overall technological innovation capability which is the inevitable trend of collaborative technological innovation for future shipbuilding industry cluster.

\section{References}

[1] Yong Hong TAO. Formation and evolution mechanism of shipbuilding industrial cluster based on symbiosis theory. Nanjing University of Science, 2005:15-16.

[2] Jian Sheng. Liu Cooperative Mode and then explore -- Based on the Symbiosis Theory Beijing Jiao Tong University (Social Science Edition), 2012, 11 (1):102-106.

[3] Pouder, R. and St. John, C.H. Geographical clusters of Firms and Innovation. The Academy of Management Review, 2003, 21(4): 192-225.

[4] Guangcai Sun. The qualitative analysis of symbiosis model of two populations. Mathematical Theory and Applications, 2003, 23(3): 64-69.

[5] DAFT R L.A Dual-Core Model of Organizational Innovation. The Academy of Management Journal, 1978, 21(2): 193-210.

[6] Shinn T, Lamy E. Paths of Commercial Knowledge: Forms and Consequences of University-Enterprise Synergy in Scientist-sponsored Firms. Research Poficy, 2006, 35(10):1465-1476.

[7] Carfiss B, Ericvon H. Modeling a Paradigm Shift: From Pro-dueer Innovation to User and Open Collaborative Innovation. http://papers.ssm.com/so13/papers.cfm? abstract_id=1502864, 2009, (11).

[8] Niki L, Panagiotis K, Sofia P,et a1.Hybrid Synergy for Virtual Knowledge Working. Handbook of Research on Electronic Collaboration and Organizational Synergy.2009,(2):83-102.

[9] Liu Dan. The technology collaborative innovation of Industry cluster's mechanisms analysis. Decision and Information, 2010, (10):152-154.

[10] Luke Bin, Wei Guo. Industrial cluster innovation and knowledge market synergies. Research management, 2010, (3):35-43.

[11] Peng Chen. The thinking of clustered enterprise collaborative innovation. Based on Statistics and Decision, 2011, (7):187-188.

[12] Zhi Leng, Ming, Zhang, He Ping. Regional economic cooperation mechanism based on symbiosis theory. Economic Review, 2007, (4): 32-33.

[13] Qi Si Shang, Quan Cao Zheng, Feng Feng. Research institutions and enterprises Symbiosis Mechanism--Based on Symbiosis Theory and Framework. Science of Science and Management, 2009, 30 (6): 15-19.

[14] Wen Xing. Zheng Symbiosis theory of creative industries clusters cultivation counter measures. Based Straits, 2010, (11): 27-29.

[15] Qiang Li, Wei Wei. Summary of applied research about symbiosis theory in the study of urban agglomerations. Yu Lin College, 2011, (1): $51-52$. 